https://www.journal-imab-bg.org

Original article
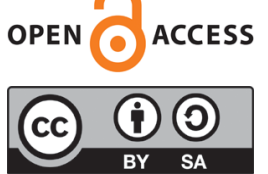

\title{
MORPHOLOGY AND STRUCTURAL CHARACTERIZATION OF HUMAN ENAMEL AND DENTIN BY OPTICAL AND SCANNING ELECTRON MICROSCOPY
}

\author{
Ekaterina Karteva ${ }^{1}$, Neshka Manchorova-Veleva ${ }^{1}$, Zhelyazko Damyanov², \\ Teodora Karteva ${ }^{1}$ \\ 1) Department of Operative Dentistry and Endodontics, Faculty of Dental \\ Medicine, Medical University -Plovdiv, Bulgaria \\ 2) Institute of Mineralogy and Crystallography "Acad. Ivan Kostov”, Bulgarian \\ Academy of Sciences, Sofia, Bulgaria.
}

\begin{abstract}
Purpose: The aim of this paper is to visualize and examine the structural features of enamel and dentin by observations in optical and scanning electron microscopes.

Material/Methods: Optical microscopic investigations were carried out on crown and root dentin of intact human teeth, extracted for orthodontic or periodontal reasons. The prepared samples were examined in transmitted and reflected light by Leitz Orthoplan-Pol polarizing microscope with digital image attachment using observations in plane polarized light, crossed nicols (polars) and through $\lambda$ plate phase-advancing compensator. Gold-coated freshly broken pieces from the same samples were examined by Philips 515 scanning electron microscope (SEM) operated at 30 kilo electron volts (keV).

Results: Transmitted light photomicrographs of enamel were obtained, showing detailed images of structural characteristics like enamel spindles, tufts, lamellae and Hunter-Shreger bands. The images from dentin visualized the lateral canals, mantle dentin, ortodentin, globular dentin and granular dentin. The SEM images showed cross-sectional and longitudinal images of the dentinal tubules, peritubular dentin and the collagen network with hydroxyapatite crystals.

Conclusions: The results of this study showed that the morphostructural characteristics of the hard dental tissues could be successfully observed and studied by the main techniques of polarizing optical microscopy and SEM. The observations provided highly-contrast, detailed and informative images of enamel and dentin.
\end{abstract}

Keywords: SEM, dentin, enamel, morphology, structure, optical microscope

\section{INTRODUCTION}

Enamel is the most mineralized substance in the human body. Its width varies in different tooth regions, from 2 $\mathrm{mm}$ in the incisal edge of frontal teeth, up to $2.4-3 \mathrm{~mm}$ in the molar cusps [1]. Since enamel is translucent, its colouring depends on the colour of the underlying dentin, the width of the enamel layer and the presence of discolou- rations. The transparency of enamel is also influenced by the stage of mineralization and its homogeneity.

The enamel consists of 95-98 wt.\% mineral content, mostly hydroxyapatite, 1-2 wt.\% organic matter, and about $4 \mathrm{wt}$ \% water. It is composed of enamel prisms - about 5 million in incisors and up to 12 million in molars [2]. Their path is uninterrupted, starting from the enamel-cemental junction (ECJ) and ending at the enamel surface or in the aprismatic layer. Their direction is parallel to the long axis of the tooth in the incisal edge and the molars cusps. Along the lateral regions of the crown, their direction is oblique to the long axis, whereas in the cervical region they become perpendicular. In the internal enamel regions, they have a distinct S-shaped curve. Enamel is brittle, with a high elasticity modulus, but little tensile strength. It is supported by the dentin, which has a lower elasticity modulus and can withstand higher values of masticatory pressure due to its unique structure.

Dentin structure is responsible for the mechanical properties of the tooth. Dentin consists of $75 \%$ inorganic material, $20 \%$ organic matter and about $5 \%$ water and other substances. Its hardness is only about $1 / 5$ of that of enamel, with its highest values near the enamel cemental junction. Its modulus of elasticity is about $1,67 \times 10^{6} \mathrm{PSI}$, which helps in support of the brittle enamel [3,4]. Dentin is secreted and formed by odontoblasts, with its main morphological structure - the dentinal tubule [4].

Due to their crystalline structure, relative transparency and anisotropy, enamel and dentin can be observed and studied by the techniques of polarizing optical microscopy revealing various features of their building ingredients, such as size, form of aggregates, inner structure, mutual relationships, optical characteristics, relative micro hardness, etc. [5]. In addition to the optical microscopy, the scanning electron microscopy can provide high-quality, detailed images giving information about the morphology, topography and structure of the objects studied [6]. The aim of this paper is to reveal and describe the features of enamel and dentin structures by observations in optical and scanning electron microscopes. 


\section{MATERIALS AND METHODS}

Optical microscopic investigations were carried out to reveal inner structure, size and phase relationships of crown and root dentin of intact human teeth, extracted for orthodontic or periodontal reasons. Two thin and two polished sections were prepared by standard preparation techniques from representative samples of crown and root dentin. The thin sections were about $0.03 \mathrm{~mm}$ in thickness. They were cemented to glass slides with Canada balsam. Before cutting the samples were visually oriented in a parallel and cross sectional direction. The same orientation was also used for the polished sections - the samples were cemented in the epoxy resin matrix and finely polished. The prepared sections were examined in transmitted and reflected light by Leitz Orthoplan-Pol polarizing microscope with digital image attachment using the main techniques of mineral optics study - observations in plane polarized light, crossed nicols (polars) and through $\lambda$-plate phase-advancing compensator [8]. Observations of thin sections from transparent minerals (phases) and their aggregates in plane polarized light provide information about their shape, form, grain size, quantity, color and its intensity, cleavage, inclusions, intergrowths, structures. Under crossed nicols, the anisotropic minerals (phases) show interference colors allowing to determine different optical characteristics and some structural details. The $\lambda$-plate compensator produced interference colors from higher order, thus providing advanced phase and structural recognition.

Gold-coated freshly broken pieces from the same samples were examined by Philips 515 scanning electron microscope (SEM) operated at 30 kilo electron volts $(\mathrm{keV})$ to reveal micromorphology, size and phase intergrowths of crown and root dentin's structure.

\section{RESULTS}

Fig. 1. Transmitted light photomicrographs of enamel and dentin structure in plane polarized light under parallel (A) and crossed (B) nicols.

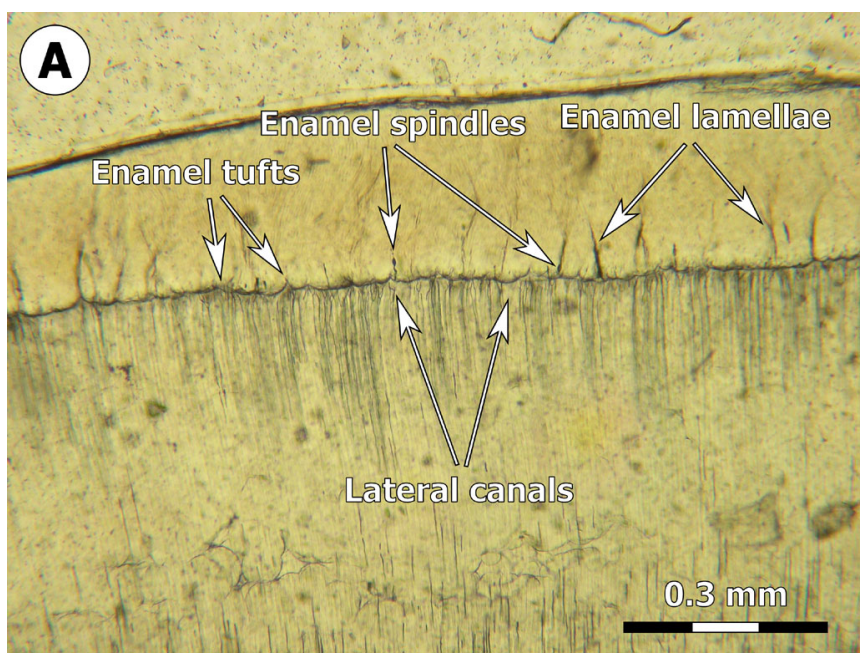

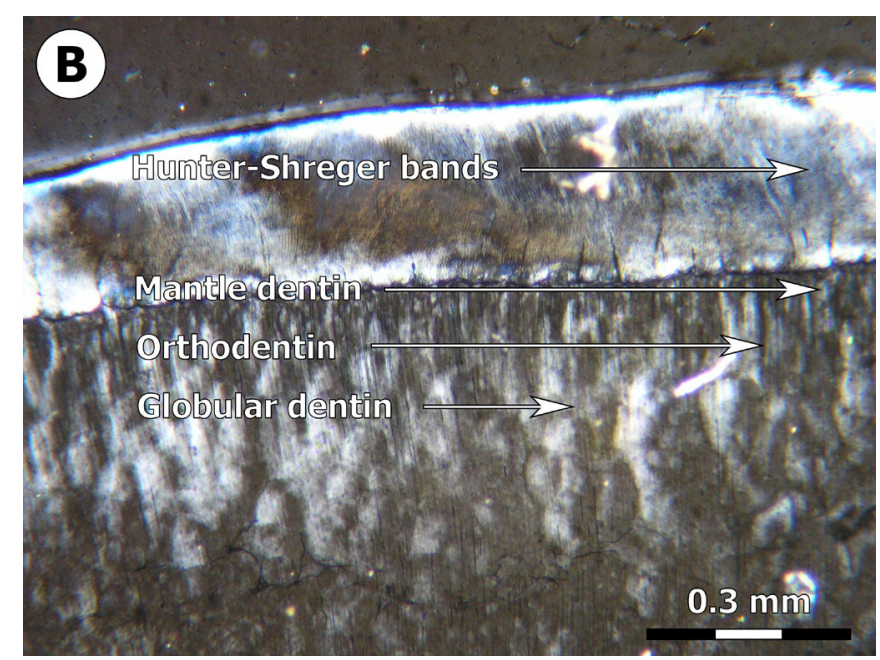

Fig. 2. Transmitted light photomicrographs of root dentin structure in plane polarized light under parallel nicols (A), crossed nicols (B), and $\lambda$-plate compensator (C). The lumen of the root canal is visible.
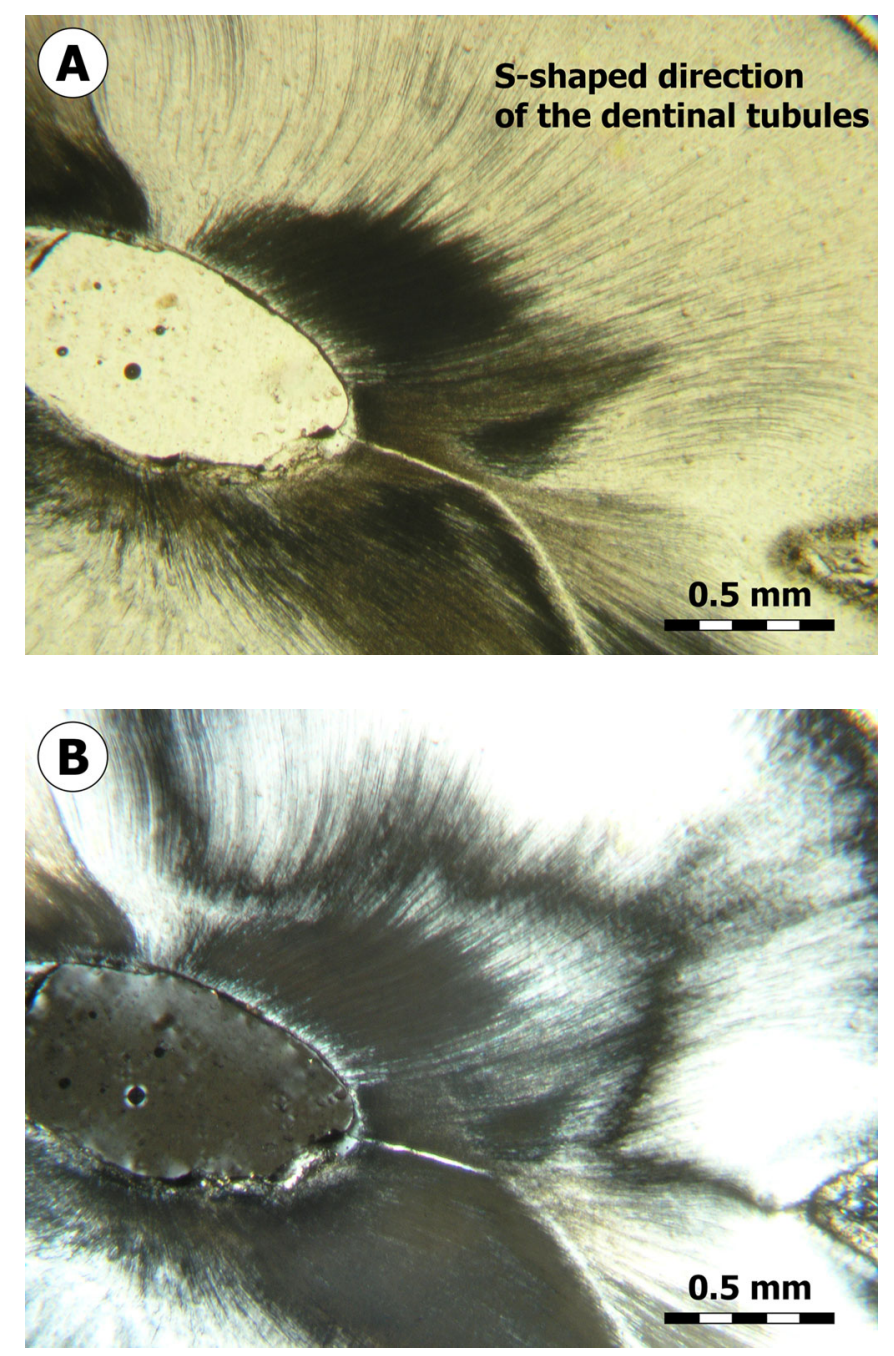


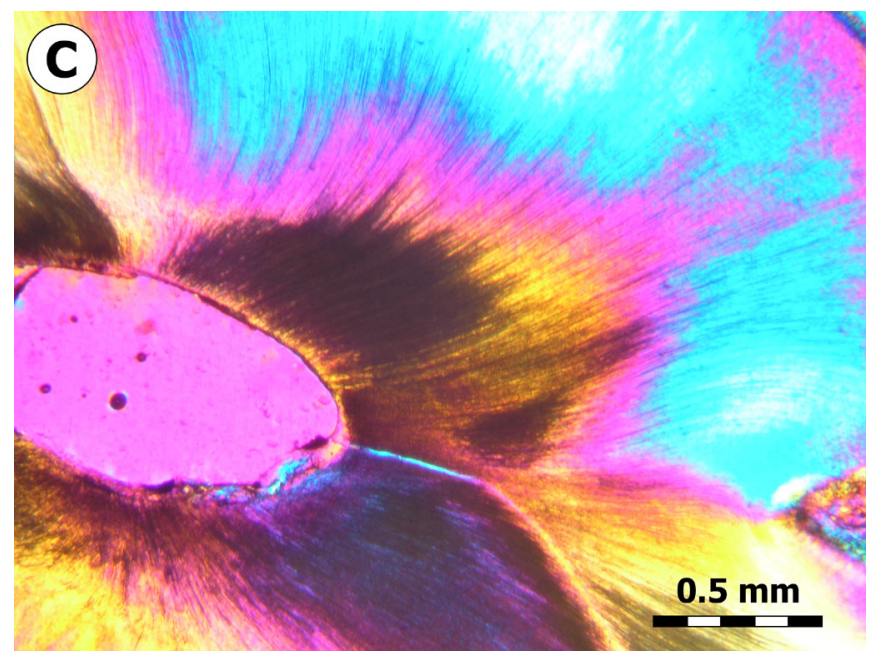

Fig. 3. Transmitted light photomicrographs of crown dentin structure in plane polarized light under parallel nicols (A), crossed nicols (B), and $\lambda$-plate compensator (C).
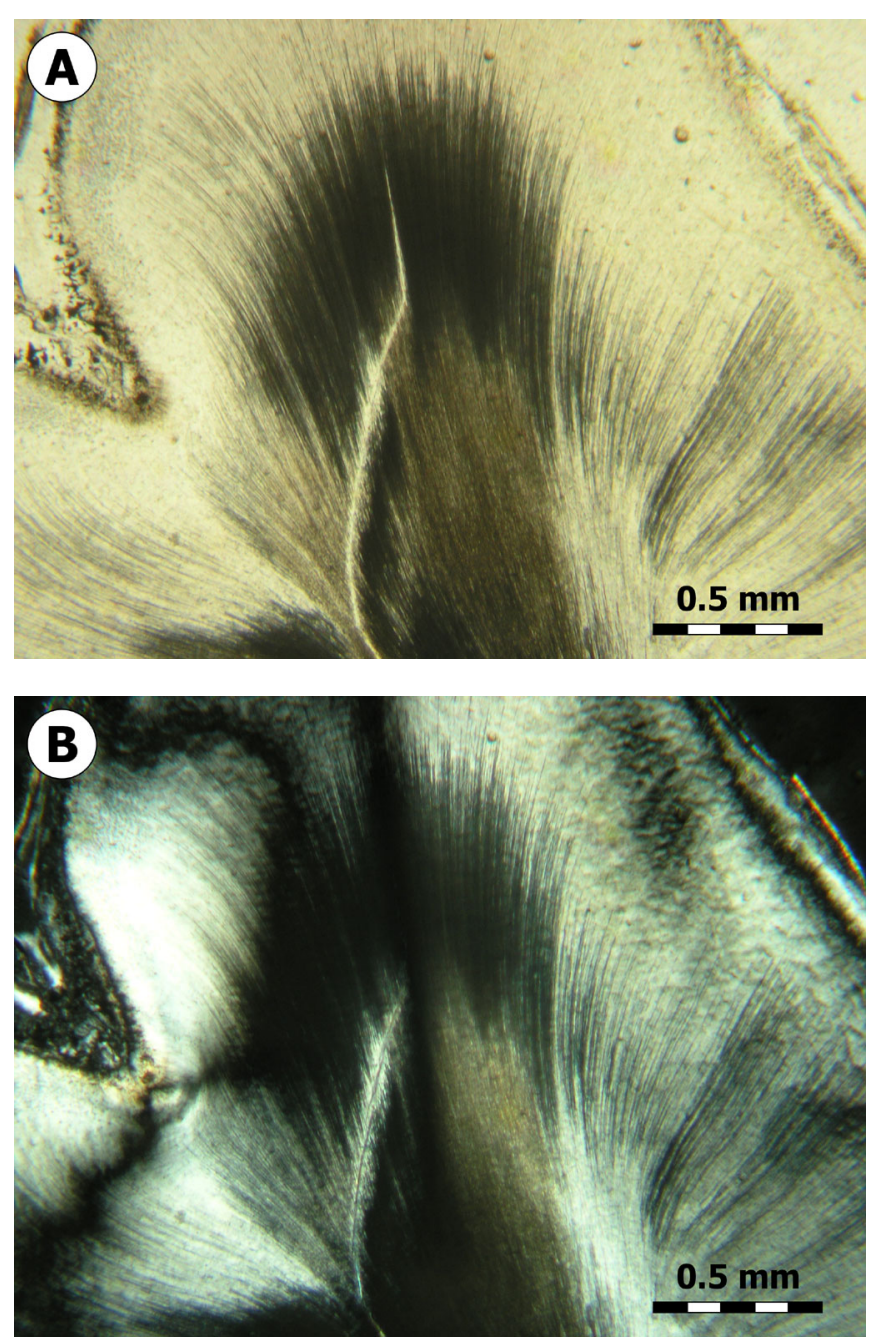

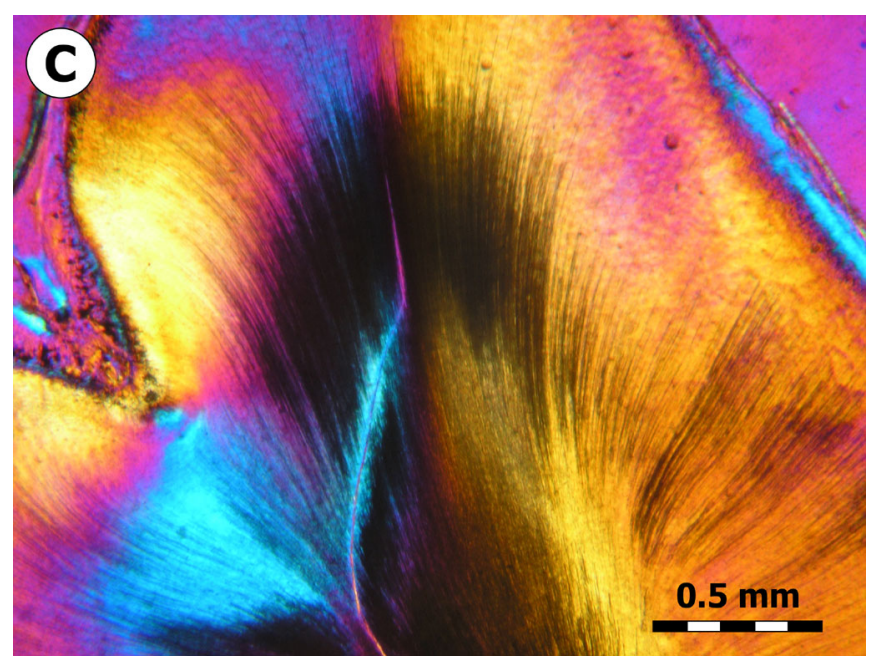

Fig. 4. Transmitted light photomicrographs of granular dentin structure in plane polarized light under parallel nicols (A), crossed nicols (B), and $\lambda$-plate compensator (C).
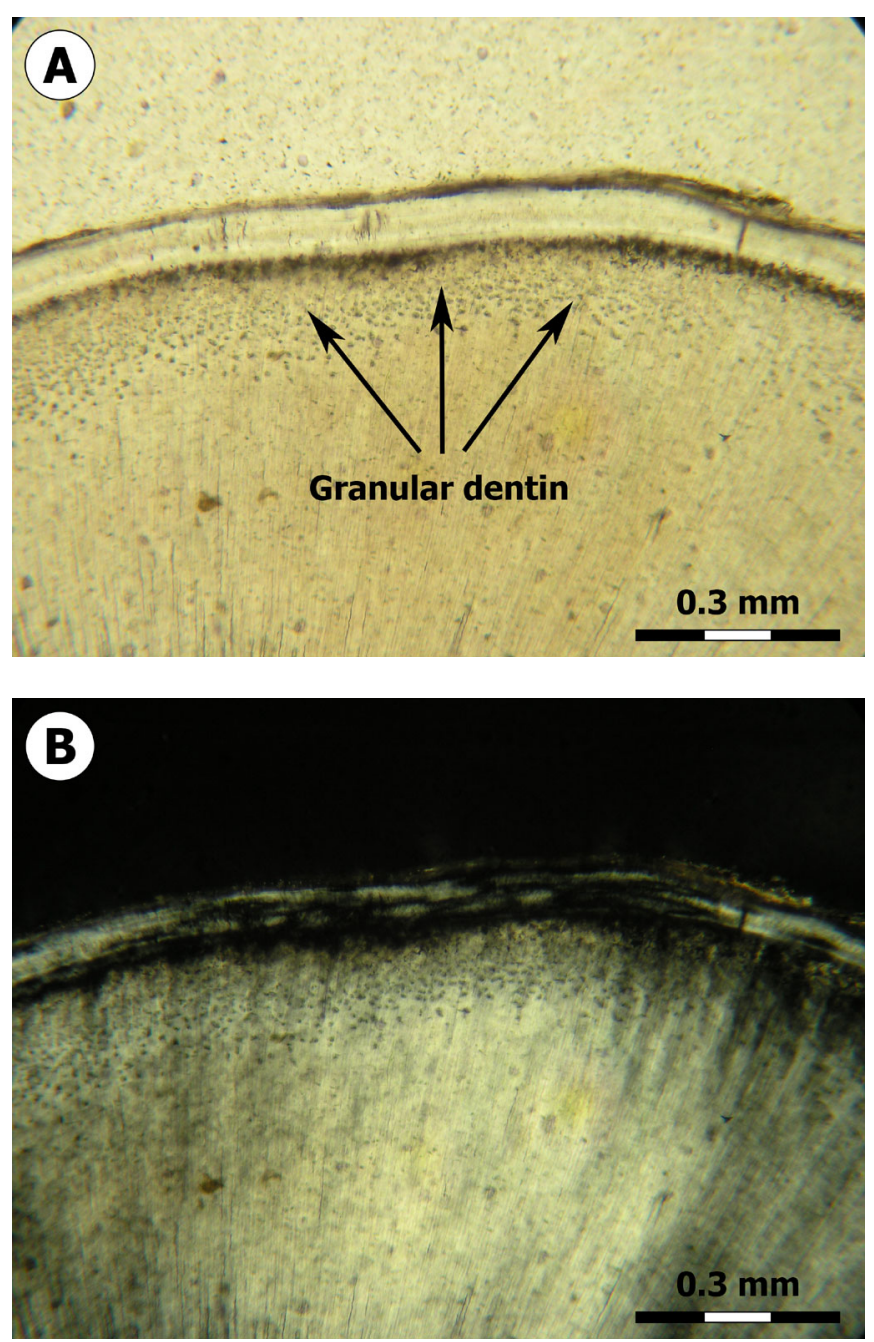


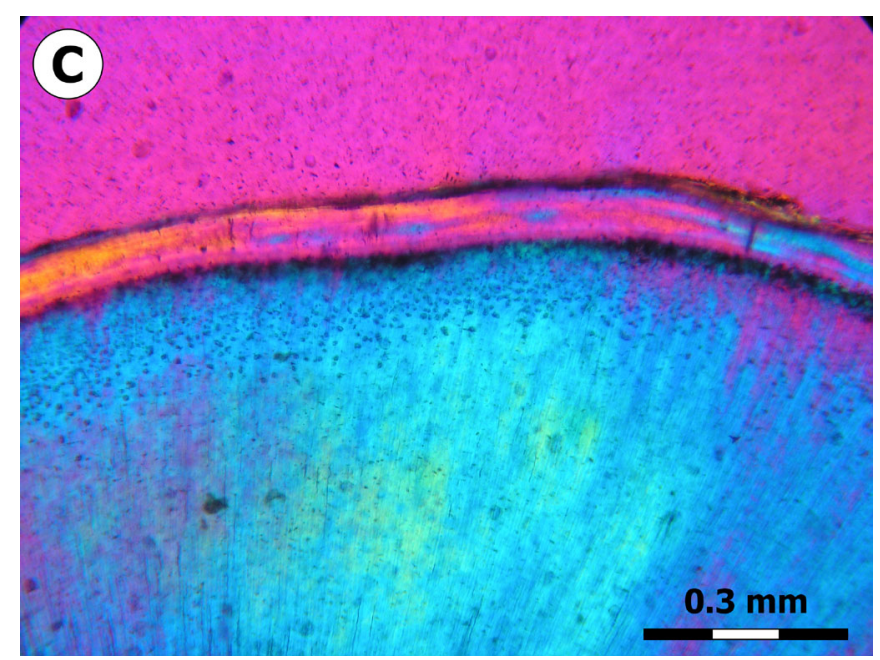

Fig. 5. Transmitted light photomicrographs of root dentin structure in plane polarized light under parallel nicols (A), crossed nicols (B), and $\lambda$-plate compensator (C). A distinct atubular zone is visible.
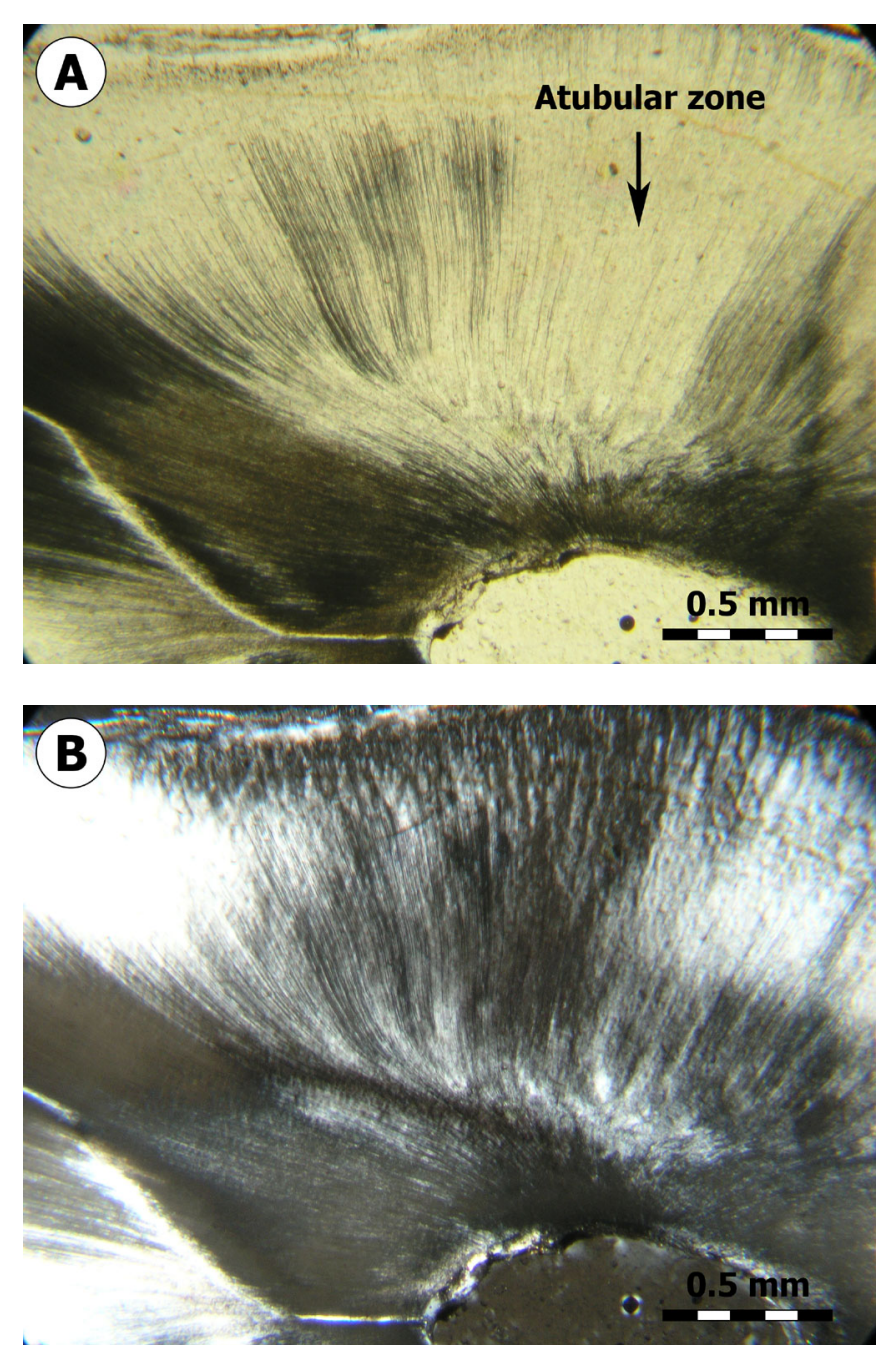

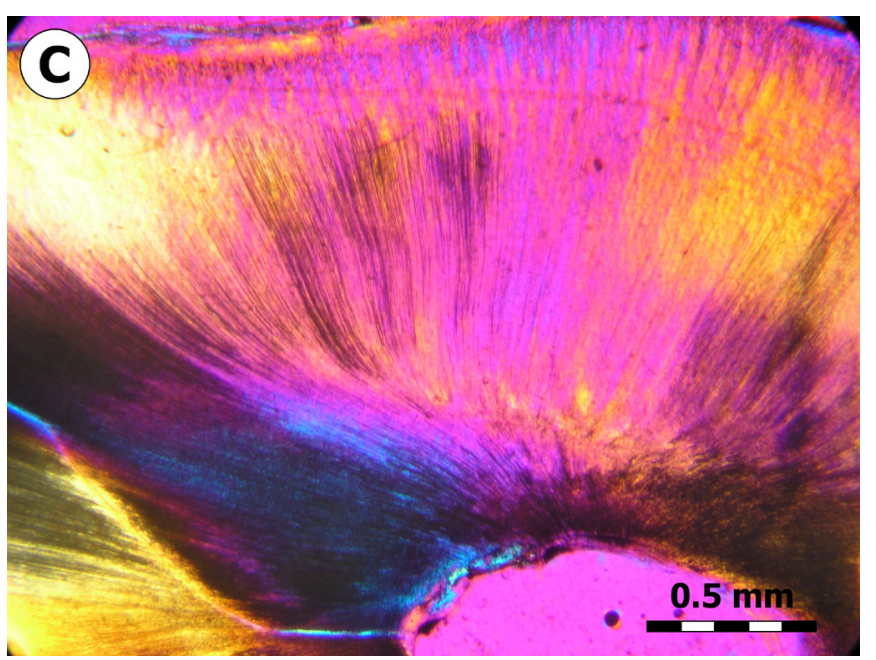

Fig. 6. Secondary electron (SE) photomicrographs of coronary dentin (A) and root dentin (B) at different magnifications.
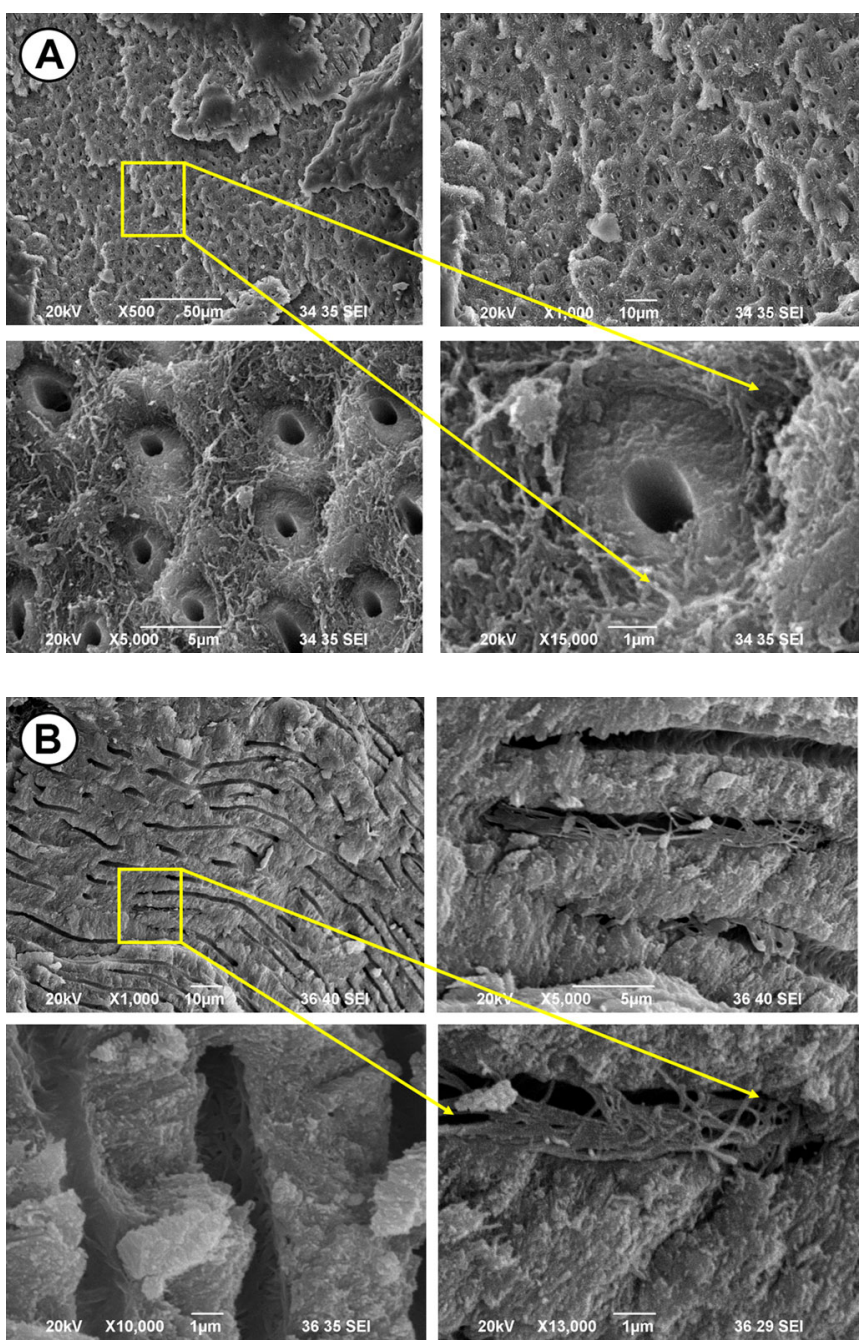
There are several characteristics of the enamel structure that became visible during this study:

1. Enamel tufts (Fig. 1A). They are located in the innermost layer of enamel, extending from the dentinoenamel junction into the enamel. The junction itself has a wavelike appearance, and the tufts start from the tips of the thus formed folds.

2. Enamel spindles (Fig. 1A). They extend from the dentinoenamel junction towards the enamel surface.

3. Enamel lamellae (Fig. 1A). The lamellae are enamel cracks, located at different levels.

4. Hunter-Shreger bands (Fig. 1B). These lines became visible under observations with crossed nicols. They are not elements of "real" enamel structure, but a result of light refraction and the wave-like direction of the prisms. The bands appear as alternating light and dark lines with different thickness.

The following layers of dentin could also be observed:

1. Mantle dentin. It is the first secreted layer of dentin, located directly below the DEJ (Fig. 1B).

2. Orthodentin. This is the so-called "dentin proper".

3. Globular dentin (Fig. 1B). It is located between the mantle dentin and orthodentin.

4. Predentin. This is the newly-secreted, not yet mineralized dentin matrix, located just above the pulp.

5. Granular dentin (Fig. 4). It is located on the surface of the root dentin, under the cement layer. It is also called Tomes granular layer and is visualized as lines of dark granules that lie parallel to the outer surface of the dentin.

\section{DISCUSSION}

The enamel tufts, spindles and lamellae, as well as the dentinoenamel junction (DEJ) with its numerous lateral canals, are clearly visible on Fig. 1A. Enamel tufts are low-mineralized, with high organic content. They are thought to be a result of defects in ameloblasts' function and can act as "pathways" for caries progression. Spindles are formed by the entrapment of the processes of odontoblasts between ameloblasts during the tooth's development. When the ameloblasts start secreting enamel, those processes are left "enclosed" into the enamel structure. It is thought that they can act like "pain receptors", which can explain some cases of pain sensitivity during preparation. Enamel lamellae contain mainly organic matter, which can ease the penetration of acids and microorganisms in caries development. There are 2 paths for lamellae formation: a defect in ameloblasts' development or mechanical pressure after enamel maturation. Hunter-Shreger bands are located in different regions of the enamel in different teeth, due to the various direction of the prisms. In incisors, they are located near the incisal edge, whereas in molars they can be found anywhere from the cervical region till the cusps' tips [1,2].

The DEJ is a complex structure where two different tissues meet and acts to prevent the propagation of cracks from enamel into the dentin. It consists of scallops with convexities directed toward the dentin and concavities toward the enamel. According to Marshall et al. [9], the DEJ consists of three levels, with scallops of 25--100 $\mu \mathrm{m}$, microscallops of 2-5 $\mu \mathrm{m}$ and a smaller scale structure.

The morphological structure of dentin is defined by the dentinal tubule. The tubules are visible on our scanning electron microscopy images in two sections - longitudinal and cross-sectional (Fig. 6). The tubules are formed during dentinogenesis around the odontoblasts' processes (Tomes processes). They originate in the zone above the pulp chamber, pass through the whole width of the dentin and terminate at the DEJ. The tubules are more densely packed near the pulp, whereas near the DEJ their lumen decreases and the intertubular spaces increase. Each tubule is enveloped in a highly mineralized layer of peritubular dentin. In between the tubules, the less mineralized intertubular dentin is located. The odontoblasts' processes branch off in numerous lateral processes that create lateral canals (canaliculi) (Fig. 1A) [10, 11]. The cross sectional images with the optical microscope show the S-shaped direction of the dentinal tubules (Fig. 2). It resembles the path of the enamel prisms and increases the tooth's resilience to masticatory pressure.

Mantle dentin is highly mineralized, with traces of organic material only, as there are no disturbances or defects during its formation [12] (Fig. 1B). Korff fibers are abundant, which aids in the close alignment of hydroxyapatite crystals. Its thickness is about 15-30 $\mu \mathrm{m}$. Compared to the other zones of dentin, it has fewer tubules. Orthodentin is less mineralized compared to mantle dentin. Korff fibers are fewer, with more $\beta$-fibers, secreted from the odontoblasts [13]. They are scattered, which reflects on the proper mineralization of this layer. Globular dentin is the least mineralized layer of the three, appearing as lighter rounded areas (Fig.1B). The archlike darker areas, visible in between the globular dentin, are considered a result of incomplete mineralization, where the globules of dentin did not fuse completely. This is the interglobular dentin and is most common in the coronal dentin, near the DEJ and in dentinogenesis imperfecta. These areas are also known as Chermak's zones [14]. In predentin, separate globules can be visible, which is a sign of commencing mineralization [13]. Granular dentin might be a result of the disorientation of odontoblasts during root dentinogenesis, or an increased globular layer with larger interglobular spaces (Fig. 4).

On Fig. 5 an atubular zone can be traced. This zone is located in the root dentin in an intact tooth sample. Usually, such zones are a result of the occlusion of dentinal tubules due to carious decay or abrasion and are callled "tertiary" or "reactionary" dentin. In our samples, however, such conditions are not present. A possible explanation of the observed microscopic images can be found in the genesis and morphology of transparent dentin. It is characterized by smaller crystallite size, which is a result of the spe- 
cific conditions during its formation. According to the literature, it is progressively accumulated with ageing in vital, as well as non-vital teeth.

Transparent dentin is physiologically formed throughout the lifespan of the tooth [15]. During its formation, accumulation of mineral substances in the lumen of dentinal tubules occur, which resembles the formation of sclerotic dentin. Its deposition begins 3-4 years after the eruption of the tooth, first in the apical part of the root and then more coronally, which can explain its location in our root sample. The amount of transparent dentin increases with age [16]. Its name is derived from its optical qualities [17]. The most popular statement for the origin of transparent dentin discusses the transportation of minerals from the intertubular matrix towards the dentinal tubules. This process is called "dissolution - reprecipitation" of the mineral content $[18,19]$. According to that view, peri- and intertubular dentin are the sources of calcium ions released under the influence of a certain event (pulp hypoxia, apoptosis) and then reprecipitated into mineral content that occludes the tubules.
The SEM images show areas in coronary and root dentin at different magnifications (Fig. 6). The coronary dentin photomicrographs show cross-sectional images of the dentinal tubules with their lumen (Fig. 6A). The peritubular dentin is visible, as well as a complex network of collagen fibers with scattered hydroxyapatite crystals, forming the intertubular dentin. The root dentin photomicrographs show the dentinal tubules in a longitudinal section, with remnants of collagen fibers forming the peritubular dentin in some of the sectioned zones (Fig. 6B).

\section{CONCLUSIONS}

The results of this study showed that the morphostructural characteristics of the hard dental tissues could be successfully observed and studied by the main techniques of polarizing optical microscopy and SEM. The observations provided highly-contrast, detailed and informative images of enamel and dentin, proving useful for the future study of dental tissues in both norm and pathology.

\section{REFERENCES:}

1. Garg N, Garg A. Textbook of Operative Dentistry. 3rd edition. Jaypee Brothers Medical Publishers. 20 July 2015. [Internet]

2. Ritter AV. Sturdevant's Art and Science of Operative Dentistry. 7 th Edition. Mosby. 24th January 2018. [Internet]

3. Kinney JH, Balooch M, Marshall SJ, Marshall GW Jr, Weihs TP. Hardness and Young's modulus of human peritubular and intertubular dentin. Arch Oral Biol. 1996 Jan;41(1):9-13. [PubMed] [Crossref]

4. Kinney JH, Marshall SJ, Marshall GW. The mechanical properties of human dentin: a critical review and re-evaluation of the dental literature. Crit Rev Oral Biol Med. 2003; 14(1):13-29. [PubMed]

5. Markaki Y, Harz H. Light Microscopy: Methods and Protocols. Humana Press. 2017. [Crossref]

6. Goldstein J, Newbury DE, Echlin P, Joy DC, Romig Jr. AD, Lyman CE, et al. Scanning electron microscopy and X-ray microanalysis: a text for biologists, materials scientists and geologists. Springer Science \& Business Media, 2012. [Crossref]

7. Horisberger M. Colloidal gold: a cytochemical marker for light and fluorescent microscopy and for transmission and scanning electron microscopy. Scan Electron Microsc. 1980; (Pt 2.):9-31. [PubMed]

8. Kerr PF. Optical Mineralogy, 4th Edition. New York, McGraw-Hill. 1977; 492 pp.

9. Marshall SJ, Balooch M, Habelitz S, Balooch G, Gallagher R, Marshall GW. The dentin-enamel junction-a natural, multilevel interface. J Eur Ceram Soc. 2003; 23(15):2897-2904. [Crossref]

10. Kaye H, Herold RC. Structure of human dentine - I:Phase contrast, polarization, interference and bright field microscopic observations on the lateral branch system. Arch Oral Biol. 1966 Mar;11(3):355-68. [PubMed] [Crossref]

11. Mjor IA, Nordahl I. The density and branching of dentinal tubules in human teeth. Arch Oral Biol. 1996 May;41(5):401-12. [PubMed] [Crossref]

12.Berman LH, Hargreaves KM. Cohen's Pathways of the Pulp Expert Consult. 11th Edition. Mosby. 2nd October 2015. [Internet]

13. Linde A, Goldberg M. Dentinogenesis. Crit Rev Oral Biol Med. 1993; 4(5):679-728. [PubMed]
14. Fehrenbach M, Popowics T. Illustrated Dental Embryology, Histology, and Anatomy. 4th edition. Saunders. 2nd February 2015. [Internet]

15. Carvalho TS, Lussi A. Age-related morphological, histological and functional changes in teeth. J Oral Rehabil. 2017 Apr;44(4):291-298. [PubMed] [Crossref]

16. Vasiliadis L, Darling AI, Levers BG. The amount and distribution of sclerotic human root dentine. Arch Oral Biol. 1983; 28(7):645-9. [PubMed] [Crossref]

17. Porter AE, Nalla RK, Minor A, Jinschek JR, Kisielowski C, Radmilovic $\mathrm{V}$, et al. A transmission electron microscopy study of mineralization in age-induced transparent dentin. Biomaterials. 2005 Dec;26(36): 765060. [PubMed] [Crossref]

18. Natusch I, Pilz ME, Klimm W, Buchmann G. Transparent dentinal sclerosis and its clinical significance. Zahn Mund Kieferheilkd Zentralbl. 1989;77(1):3-7. [PubMed]

19. Vasiliadis L, Darling AI, Levers BG. The histology of sclerotic human root dentine. Arch Oral Biol. 1983; 28:693-700. [PubMed] [Crossref] 
Please cite this article as: Karteva E, Manchorova-Veleva N, Damyanov Z, Karteva T. Morphology and structural characterization of human enamel and dentin by optical and scanning electron microscopy. J of IMAB. 2019 OctDec;25(4):2744-2750. DOI: https://doi.org/10.5272/jimab.2019254.2744

Received: 17/05/2019; Published online: 29/10/2019

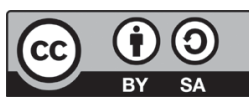

Address for correspondence:

Ekaterina Karteva,

Department of Operative Dentistry and Endodontics, Faculty of Dental Medicine, Medical University -Plovdiv,

7, Dimcho Debelianov str., Plovdiv 4000, Bulgaria.

E-mail: katya.kk@gmail.com 